\title{
Attitudes of women in Scotland to contraception: a qualitative study to explore the acceptability of long-acting methods
}

\author{
Anna Glasier, Jane Scorer, Alison Bigrigg
}

\begin{abstract}
Background and methodology Long-acting reversible contraception (LARC) (i.e. injections, implants and intrauterine methods) has the potential to reduce unintended pregnancies but in the UK these methods are under-used. To inform a campaign planned to increase awareness of LARC, eight focus discussion groups were held with 55 women in two cities in Scotland, UK. Trained interviewers sought spontaneous views of unintended pregnancy and contraception in general, and condoms and pills in particular, and attitudes towards health professionals giving contraceptive advice. Attitudes towards LARC were discussed both before and after women were given detailed information about the methods.
\end{abstract}

Results Women recognised the importance of using contraception but admitted to taking risks. Pills and condoms were familiar and acceptable despite undesirable side effects. Women were poorly informed about LARC, had firm but incorrect beliefs about their safety and side effects, disliked any method which involved an invasive procedure and/or vaginal examination, and had rather a low opinion of advice given by health professionals. Accurate information was not wholly successful in dispelling negative views of LARC.

Discussion and conclusions Many factors influence contraceptive choice. Attitudes towards methods are complex and may be difficult to change. Some barriers to LARC, including the need to see a health professional, cannot be overcome but giving more information about ease of use, reversibility, effects on weight and the positive experiences of other women, as well as describing these methods as lasting rather than longacting, may help improve acceptability.

Keywords attitudes, contraception, health professionals, long-acting, views

J Fam Plann Reprod Health Care 2008; 34(4): 213-217 (Accepted 5 June 2008)

\section{Introduction}

Although contraceptive prevalence rates in the developed world are high, ${ }^{1}$ unintended pregnancy is common. In the UK the most popular contraceptives are condoms and pills; both rely on consistent and correct use and demand strict compliance for their effectiveness. Long-acting reversible methods of contraception (LARC) [i.e. intrauterine devices/intrauterine system (IUDs/IUS), implants and injectables] are highly effective, depend much less - if at all - on compliance for their effectiveness, and increasing their use has the potential to reduce unintended pregnancy. ${ }^{2}$ Health professionals working in primary care settings in the UK have reservations about the long-term use of Depo-Provera ${ }^{\circledR}$, and about the side effects and continuation rates of Implanon ${ }^{\circledR}$, and many lack the necessary skills to insert implants and intrauterine contraceptives. 3,4 Unsurprisingly then, use of LARC is low in the UK. In $2005 / 2006$ only $10 \%$ of women aged $16-49$ years had used any LARC in the previous year compared with $23 \%$ who had used oral contraception and $21 \%$ condoms. ${ }^{5}$ Uptake of

NHS Lothian Family Planning/Well Woman Services,

Edinburgh, UK

Anna Glasier, MD, DSc, Lead Clinician for Sexual Health NHS

Lothian, Honorary Professor Universities of Edinburgh and London

The Healthcare Research Partnership, Stapleford, UK Jane Scorer, BSc, RGN, Partner

\section{Sandyford Initiative/NHS Greater Glasgow \& Clyde Sexual \\ Health, Glasgow, UK}

Alison Bigrigg, FFSRH, DM, Director/Lead Clinician in Sexual Health

Correspondence to: Professor Anna Glasier, NHS Lothian

Family Planning/Well Woman Services, 18 Dean Terrace,

Edinburgh EH4 1NL, UK.

E-mail: anna.glasier@nhslothian.scot.nhs.uk

\section{Key message points}

- Women tend to choose contraceptive methods with which they are familiar and/or that their peers are using.

- Women want more information from their primary health care providers about the range of available contraceptives.

- The need for invasive procedures/vaginal examination deters women from choosing long-acting methods of contraception.

- Rethinking the focus of information about LARC, emphasising their lasting protection, reversibility and (for implants and intrauterine devices/intrauterine system) their lack of effect on weight gain may improve acceptability.

contraceptive implants, IUDs and the IUS is low in Scotland. ${ }^{6}$ Recognising the potential of LARC to prevent unintended pregnancy, measures being used to monitor implementation of the National Sexual Health Strategy in Scotland 6 include increasing the uptake of LARC, and the Department of Health in England recently launched an initiative to promote LARC use. ${ }^{7}$

The literature on acceptability of contraceptive methods is dominated by data from women already using those methods, often in the context of clinical trials. Good quality evidence specific to the UK is hard to find. Limited data suggest that most UK women know little about LARC, and prejudices - particularly about intrauterine methods - are common. ${ }^{8}$ In order to inform a publicity campaign planned to provide information about, and hopefully to increase the demand for, LARC, we undertook a number of focus group discussions among women with a lifestyle commitment that might increase the desirability of long-term contraception. The aim of the study was to improve our understanding of attitudes towards contraception and unintended pregnancy, the reasons for choosing the popular contraceptive methods and awareness, and knowledge of and potential interest in LARC. 


\section{Methods}

Sixty-four women were purposively recruited in Edinburgh and Glasgow to represent life stages that might be associated with starting or changing contraceptive use, particularly to a more effective method. The four groups comprised college students, university students, young parents and women who had completed their family. Recruitment was undertaken independently of the researchers. Women were approached through 'street' recruitment, outside colleges, universities and shopping areas and by 'passive snowball' techniques 9 whereby women were asked to volunteer friends/contacts who might be interested in participating. No more than $20 \%$ of the groups were recruited by 'passive snowballing' to avoid closed-group phenomena, resulting in groups largely comprising respondents not known to each other. Volunteers contacted the recruiter directly to express willingness to participate. All women were given information about the research in advance of participation and completed a short questionnaire about personal and contraceptive circumstances to determine eligibility. Eight focus group discussions (one of each of the life stage groups in each city) were conducted in October 2007. The focus groups lasted 2 hours, were facilitated by one of two experienced female moderators to encourage open interaction and debate, and were supported with selfcompletion exercises to capture individual responses. Initial spontaneous discussions explored determinants of contraceptive method choice and sources of information/advice; attitudes towards pregnancy and risk taking; views of providers; reasons for choosing condoms and pills; and beliefs about and attitudes towards longacting methods. This was followed by more detailed reactions to published information about LARC methods and comparisons with pills and condoms provided during the session. Group discussions were tape-recorded for textual and verbatim analysis using basic principles of content analysis. Taped discussions were transcribed in notation format, using as much verbatim material as possible. Second-stage analysis involved listings to organise the data into meaningful sections and key headings were introduced to test the underlying research questions.

\section{Results}

Fifty-five women participated in the study (nine women did not arrive for their appointment). The characteristics of the groups (including relationship and financial status, and current contraceptive use) are shown in Tables 1-4. The moderator made generalised observations about each group in respect of their typical living arrangements, social lives and knowledge of contraception. Most of the participants, except those in the university student group, originated from Scotland.

- College students were undertaking vocational studies, frequently lived at home with their parents, and had active social lives. They had limited knowledge, understanding and interest in contraception.

- University students originated from the UK, lived away from home, and had active weekend social lives. They appeared fairly knowledgeable and interested in contraception.

- Young single parents (whose first child was conceived at age 15-17 years) originated from Scotland, were at college or doing part-time vocational work, and lived independently but were reliant on their mothers for childcare support. They had limited social lives, regretted and highlighted the negative consequences of early, unplanned pregnancy, and showed an interest in contraception.
Table 1 Focus group categories employed in the study

\begin{tabular}{|c|c|c|c|}
\hline \multirow{2}{*}{$\begin{array}{l}\text { Focus group category } \\
\text { (age range) }\end{array}$} & \multicolumn{3}{|c|}{ Number of women $(n)$} \\
\hline & Edinburgh & Glasgow & Total \\
\hline $\begin{array}{l}\text { College students } \\
\text { (16-18 years) }\end{array}$ & 7 & 7 & 14 \\
\hline $\begin{array}{l}\text { University students } \\
\text { (19-21 years) }\end{array}$ & 7 & 6 & 13 \\
\hline $\begin{array}{l}\text { Young parents } \\
\text { (18-23 years) }\end{array}$ & 6 & 7 & 13 \\
\hline $\begin{array}{l}\text { Women with completed } \\
\text { family ( } 25-35 \text { years) }\end{array}$ & 8 & 7 & 15 \\
\hline Total & 28 & 27 & 55 \\
\hline
\end{tabular}

Table 2 Relationship status of women involved in the study

\begin{tabular}{lccc}
\hline Relationship status & \multicolumn{3}{c}{ Number of women $(\boldsymbol{n})$} \\
\cline { 2 - 4 } & Edinburgh & Glasgow & Total \\
\hline Single & 3 & 4 & 7 \\
Early relationship & 17 & 11 & 28 \\
Established relationship & 8 & 12 & 20 \\
Total & 28 & 27 & 55 \\
\hline
\end{tabular}

Table 3 Mortgage commitment of women involved in the study

\begin{tabular}{lccc}
\hline Mortgage commitment & \multicolumn{3}{l}{ Number of women $(\boldsymbol{n})$} \\
\cline { 2 - 4 } & Edinburgh & Glasgow & Total \\
\hline Have commitment & 6 & 9 & 15 \\
Thinking about commitment & 2 & 7 & 9 \\
None foreseen & 20 & 11 & 31 \\
Total & 28 & 27 & 55 \\
\hline
\end{tabular}

Table 4 Current contraception status of women involved in the study

\begin{tabular}{llll}
\hline Contraceptive method & \multicolumn{3}{l}{ Number of women $(\boldsymbol{n})$} \\
\cline { 2 - 4 } & Edinburgh & Glasgow & Total \\
\hline Condoms & 17 & 14 & 31 \\
COC (pill) & 10 & 9 & 19 \\
Injection & 1 & 2 & 3 \\
Implant & 0 & 2 & 2 \\
Total & 28 & 27 & 55 \\
\hline
\end{tabular}

$\mathrm{COC}$, combined oral contraceptive.

- Women with completed families were in established partnerships or married with children aged 3-16 years, lived mainly in owned housing, and were working. These women had some personal interest in contraception but were more interested in methods suitable for their teenage children.

\section{Determinants of method choice}

Contraceptive choice was based on perceptions of safety, efficacy and 'reliability' of protection against pregnancy and disease, ease of use, side effects (particularly visible effects such as weight gain or acne), reversibility and accessibility. Duration of action appeared to have no influence on choice. All groups of women identified the need to feel "safe" and "protected" as important drivers for contraceptive uptake.

Box 1: Determinants of contraceptive choice
"We want safety - no pregnancy and no diseases."
(College student)
"Take it once and forget about it." (College student)
"You need to get it easily - trying to make a doctor's
appointment is hard." (Young parent)
"You just want to come off it and be able to have a baby."
(Young parent)




\section{Attitudes towards pregnancy and risk taking}

All women stressed the importance of contraception. The majority had actively decided not to have children at this stage in their life; unplanned pregnancy would represent a "shock" and a "disaster" especially for women under 25. For college students, unplanned pregnancy raised concerns about body image ("get fat"), social life ("have to stay in") financial restriction and single parenthood. University students were more concerned about their studies being interrupted and coping emotionally and financially with an unplanned pregnancy, but were less concerned about body image. Young parents described the devastation of having a child, how parenthood "turns your life upside down", creates constant hard work with limited sleep, body changes, depression, social isolation, lack of money and difficulties completing studies or attending work. All young parents admitted that greater consideration would have been given to abortion had they known the effect of unplanned pregnancy on their body and their lives.

\section{Box 2: Attitudes towards pregnancy and motherhood}

"I just couldn't cope with it ... l'd rather be safe than sorry." (University student)

"I want to be old, 22 or so, when I have children." (College student)

"It was a real shock ... it's a different life compared to my friends." (Young parent)

"I was a bit silly with the pill and I didn't know what it would actually be like. You get no sleep, stretch marks, sick for 9 months, then there's the birth ... there's nothing out there to tell you about it." (Young parent)

Despite strong belief in the need for contraception, all women indicated that they had taken, or were prepared to take, risks with contraception. Young parents were the least likely to say they would take risks, preferring to take control or even avoid sex rather than risking pregnancy. Risk-taking behaviour was usually induced by alcohol; "getting carried away with the moment"; having no contraception available; believing that "it won't happen to me"; or by embarrassment and social pressure to "be like others".

Understanding about the risk of pregnancy was poor. When informed that $80-90 \%$ of women may get pregnant within 1 year, the information had the power to shock women, especially if translated into the short term (i.e. 1 month, 1 night).

Box 3: Attitudes towards the risk of pregnancy
"You don't care if you get drunk." (College student)
"You want to be the same as your friends - you don't want to be
left behind or be different." (Young parent)
"I forget the pills about seven times a month. I take two together
even though I know it's wrong." (College student)
"You think it won't happen to you but it could ... it helps put it in
perspective especially if you focus on that one night." (University
student)

\section{Views about health professionals}

Many women wanted to avoid having to see a doctor, citing embarrassment [especially with older, male or family general practitioners (GPs)], concern about confidentiality, and difficult/inconvenient access. There was a preference for consultation with female health care professionals, but limited awareness of the role of nurses. Despite praise for GPs in managing contraceptive problems/side effects, there was an overall perception that consultations in primary care (by GPs) lacked education and information to make choices. Women disliked initiating discussions about contraception with a health care professional. Embarrassed about admitting sexual activity, women tended to present by asking for the "pill" or citing "period problems", terms that to them were synonymous with a request for contraception. They felt that in response they were "given what they asked for" rather than discussing wider contraceptive choices.

Women want to be offered contraceptive choices and to feel equipped with sufficient information to make informed decisions. They felt that health care professionals should ask the right questions, be proactive and questioning, avoid assumptions and present information in an open manner. While doctors are trained to ask open questions, women want to be directed within a consultation to avoid the inherent embarrassment of "opening up" until a relationship with the doctor is formed.

Box 4: Views about health professionals

"If they have known you since a girl, it's horrible." (College student)

"When you go to the doctor you say you are having period problems in order to get the pill. I don't want to confess I'm having sex." (Young parent)

"Everyone was on the pill, so that's what I asked for - she just gave it to me ... the pill is all we know." (University student)

"Doctors need to be more open with their questions about sex rather than leaving us to lead the discussions." (Young parent)

\section{Views of condoms and pills}

Condoms and pills were perceived to be effective and "protective" and were considered "normal". For many these methods were all they knew. Specifically condoms were perceived as offering protection against pregnancy and disease, easy ("pick up and put down"), quick ("you get into a pattern with them"), easily accessible, enhancing stimulation, and free from hormones. There was, however, an overriding perception that condoms are inconvenient, affect spontaneity, can burst, and are expensive if purchased over the counter. Ease of access to contraception was an important consideration for all women, and for some availability from "anonymous" over the counter sources was important. Condoms enabled avoidance of contact with a health professional, which could be embarrassing and necessitated making an appointment, which some women clearly found "difficult".

Contraceptive pills were perceived as effective, known, convenient and easy to ask for, resulting in lighter, regular periods, and more effective and less 'messy' than condoms. However, women acknowledged that contraceptive pills require regular pill taking, are not completely effective (95-97\%), have hormonal side effects (headache, sickness and weight gain were mentioned) and do not protect against sexually transmitted infections (STIs). Women commonly admitted to forgetting to take up to three pills each month.

Box 5: Attitudes to condoms and contraceptive pills
"It's easier than taking a pill every day ... but it brings
awkwardness to a situation." (Young parent)
"It's safer - when you don't expect to have sex at least you are
covered." (College student)
"I don't like the idea of having to take it all the time." (University
student)
"Going on the pill seems normal - it's what your friends do."
(Young parent)

Knowledge of and attitudes towards LARC methods

During the spontaneous discussion within the focus groups it became clear that while the majority of women in the study were aware of long-acting methods of contraception (understood as being injections, implants, 'coil' and sterilisation), they had limited knowledge of individual 
methods, and relied heavily on negative, second-hand stories from friends and the media. Knowledge of DepoProvera ${ }^{\circledR}$ included the fact that it lasts 3 months, is not reliant on regular/daily compliance ("foolproof"), is easy and potentially suitable for all ages; but there was a strongly expressed fear/dislike of needles, and side effects (headaches, premenstrual tension symptoms, bleeding changes, weight gain, bone effects were all mentioned). Women also expressed concern about the return to fertility after taking Depo-Provera, and told stories about difficulty getting appointments and of its use being restricted to 5 years.

Contraceptive implants were perceived slightly more favourably than was Depo-Provera. Women knew that implants last for 3 years (and up to 5-10 years for some implants), are easy, "no need to remember" and suitable for all ages. But for many of the participants, insertion and removal in the arm represented a "disgusting" concept and the method was felt to be too long term for younger women.

\section{Box 6: Attitudes towards contraceptive implants \\ "It's less hassle - you don't have to remember." (College student) \\ "Horrible ... you could see it and play with it." (Young parent) \\ "I don't like the idea of 3 years - it sounds too long." (College student)}

Intrauterine contraception was perceived negatively with no differentiation between IUDs and the IUS. While IUDs were known to be long lasting (5-15 years), there was a perception of poor efficacy ("heard of failures"), concern about the need for a vaginal examination, discomfort, expulsion, side effects (infection and weight gain were mentioned), effects on long-term fertility, and lack of protection against STIs. IUDs/IUS were perceived to be most suitable for women who have had a child or completed their family, though they were not always a particularly attractive proposition for these women either.

\section{Box 7: Attitudes towards intrauterine contraceptive}

\section{methods}

I don't like the idea of something inside me." (University student) "It's not something I fancy ... it's a foreign body." (Completed family)

"It's what my mother would use ... it's for old women." (College student)

After being given detailed information about LARC, women acknowledged that their knowledge was limited and frequently second-hand and the information leaflets were perceived as useful and informative (and many women took copies away). However, concerns about LARC were still evident, especially in relation to intrauterine methods. There were positive responses to ease of use ("no hassle, forget about it"), efficacy and to side effects (especially return to fertility and effects on periods) but women still expressed concern about the duration of action and were unhappy with the term 'longacting', which had implications for them of a possible negative effect on the return of fertility, and consequently they preferred the idea of methods being 'lasting'. They were still concerned about the insertion and removal procedures, failure rates (referring once again to stories of pregnancies among users of LARC), and lack of STI protection, and they were also nervous about these methods being less known about and the requirement to attend a doctor.

\section{Box 8: Attitudes towards information about LARC}

"A shorter method seems easier but a longer method is less hassle." (College student)

"With a long-term method, you'd worry what it was doing to your insides." (Young parent)

"I don't want to feel not fertile." (University student)

"I hate the idea of a stranger poking around down there. That's worse than having something out in your arm." (Young parent)

Asked directly and indicated by a show of hands, $25 \%$ of the focus group participants might be interested in LARC in the future, particularly university students and young parents. All the women were interested in the concept of categorising contraception by duration of action and all wanted more information and more choice, and to hear about personal experiences. However, for greater consideration of LARC methods in the future, women want help from health care professionals to make informed choices in an appropriate, non-judgemental and easily accessible manner.

\section{Discussion}

A wide range of factors affect contraceptive choice and uptake worldwide and method use varies considerably between countries. For example, while the IUD is chosen by $17 \%$ of women using contraception in Sweden, it is used by less than $1 \%$ of women in the USA. Injectable progestogen-only contraception is the most popular method in South Africa and Thailand but hardly used in France, Spain or Italy. Some 24\% of couples in Turkey rely on withdrawal, a method which most providers in the UK regard as ineffective and not something to be promoted. That the two most popular contraceptives in the UK are condoms and the pill is unfortunate since inconsistent and incorrect use of both methods is common. In the UK and the USA the majority of unintended pregnancies occur among women who claim to have been using condoms or pills. ${ }^{10,11}$ Missing up to three contraceptive pills every month is common. ${ }^{12}$ Women in our study admitted to taking risks with contraception even when pregnancy was unwanted, and they did so repeatedly. This emphasises the need for methods that are independent of daily action for their effectiveness. In the USA the fall in teenage pregnancy rates has been attributed to the growing use of Depo-Provera. ${ }^{13}$

Women participating in this study mentioned a number of well-recognised factors that determine their choice of contraceptive method. Effectiveness, ease of use and safety are important when choosing a method. Other factors, less commonly discussed when advising women, may be equally important and more influential. Familiarity with a method is clearly important and may help explain why in so many countries a single method dominates use. Perhaps it also explains why it seems to take such a long time for a new method to become widely used. For the women taking part in this study, being on the pill was seen as the norm and they were nervous about using a method that they perceived as being 'unusual'. Health professionals need to be aware of this when describing methods that are 'new' to potential users; it may be important to make it clear that lots of women use, and are happy with, these methods.

This study illustrates too the strong influence that the experiences of other people have on method choice - even when the experience comes from friends of friends rather than from friends themselves. Lurid stories from friends or magazines that attribute unintended pregnancy or serious health problems to a contraceptive method are memorable and powerful. Sadly the media rarely tell stories of women who have had good experiences, as they don't make for eye-catching headlines. It is disappointing that providing the correct information - as we did in this study - appears to do little to shake loose these prejudices. 
Data from this study confirm that myths and misconceptions about contraceptives are common and that fear of side effects (whether real or imagined) is an important determinant of their acceptability. ${ }^{14}$ Fear of visible side effects, particularly weight gain, influences both uptake and continuation of contraception and outweighs fear of pregnancy even when unwanted. Fear of effects on future fertility is less well documented and may come as a surprise to providers who only discuss this in relation to use of Depo-Provera. Even though none of the women participating in our focus groups actively wanted to get pregnant, they were all extremely anxious to avoid any method that might jeopardise their future fertility. That the term 'long-acting', which implies positive attributes to prescribers, had negative connotations to users is important if we are to encourage the use of LARC. The term 'lasting' had much more positive meaning, implying reliability and quality, and arguably it should become the norm in describing these contraceptive methods.

Lack of protection against STIs was regarded as a disadvantage of LARC. It is not only potential users that express concerns about STI risks, but it is hard to see how to get round this problem other than to recommend dual protection, which tends to be rarely used. In a study of teenagers using Norplant ${ }^{\circledR}$, the pill or condoms, Darney and colleagues demonstrated that although use of Norplant was associated with a reduction in condom use, there were no differences in the rates of STIs related to the contraceptive method being used. ${ }^{15}$ The authors concluded that teenagers do not use condoms consistently enough to prevent either pregnancy or infection.

Providers have a vital role to play in determining contraceptive use, yet in this study health professionals, particularly in primary care, were described in a rather negative light. However misplaced, access to GPs was thought to be difficult and their advice rather limited. Women, even married women, were embarrassed to ask their GP for contraception as it involved admission of sexual activity. It was easier to ask for the pill rather then for contraception since "everyone takes the pill" and it was possible to claim that the pill was needed for period problems rather than for contraception. These women claimed that they did not want the GP to take them at face value when they asked for the pill but, rather, wanted information and advice about a range of methods. All too often in this situation it is likely that most GPs would simply provide the pill because it is easy and quick to write a prescription, because they too are familiar with the pill (and much less familiar with LARC) but also because that is what the woman asked for and most health professionals are taught that directive counselling (i.e. suggesting that there may be a better alternative) is wrong.

Even when detailed information about long-acting methods was made available to women in the focus groups there were still barriers to acceptability. The need to see a health professional or have a vaginal examination appeared to be important barriers that cannot easily be overcome. The invasive nature of the insertion of implants and IUDs/IUS and the need for injections of Depo-Provera should not be a barrier to a generation of young women who are happy to get tattoos and piercings even in the most intimate parts of their anatomy. Unwanted pregnancy inevitably leads to contact with health professionals and involves invasive procedures but many women do not link taking risks with contraception with getting pregnant.

Arguably more amenable to being overcome are the barriers associated with the terminology commonly used to describe LARC methods and the fears about infertility. We should probably stop describing these methods as long- acting but rather emphasise the lasting protection they confer. We should stress their reversibility and the lack of an effect on body weight. Once more people start to use them, LARC methods will become more familiar to users and providers. Women participating in these focus groups in Scotland suggested that good personal experiences (i.e. happy stories) should be used as a marketing ploy in promotional materials, and they also suggested that hard facts about the risks and consequences of unwanted pregnancy should be used to shock women into thinking harder about using contraception.

In conclusion, these focus group discussions with 55 women living in Scotland's two main cities confirm that many of them know very little about contraceptive methods other then the pill and condoms. They recognise the potential benefits of LARC for pregnancy prevention, but even when given detailed information express concern about a number of issues, some of which may be overcome by thoughtful publicity and positive, open consultations with health care professionals focusing on concerns and barriers to uptake including insertion/removal and return to fertility.

\section{Statements on funding and competing interests}

Funding Funding for this study was provided jointly by Bayer Health Care Ltd (Schering) and Schering Plough Ltd (Organon). Both companies market long-acting methods of contraception. Neither company had any input into writing the manuscript.

Competing interests None identified.

\section{References}

1 Population Reference Bureau. Transitions in World Population (Population Bulletin Vol. 59, No. 1). Washington, DC: Population Reference Bureau, 2004; 1-40.

2 National Institute for Health and Clinical Excellence (NICE). Longacting Reversible Contraception (CG30). 2005. http://www. nice.org.uk/nicemedia/pdf/CG030fullguideline.pdf [Accessed 17 January 2008]

3 Glasier A, Yan Y, Wellings K. How do health care professionals respond to advice on adverse side effects of contraceptive methods? The case of Depo Provera ${ }^{\circledR}$. Contraception 2007; 76: 18-22.

4 Wellings K, Zhihong Z, Krentel A, Barrett G, Glasier A. Attitudes towards long-acting reversible methods of contraception in general practice in the UK. Contraception. 2007; 76: 208-214.

5 Taylor T, Keyse L, Bryant A. Contraception and Sexual Health 2005/06 (Omnibus Survey Report No. 30). 2006. http://www.statistics.gov.uk/downloads/theme_health/contracepti on2005-06.pdf [Accessed 17 January 2008].

6 Information Services Division (ISD) Scotland. Key Clinical Indicators for Sexual Health: Baseline Report on Long Acting Reversible Contraception (LARC) Uptake in Scotland, 2003/04-2006/07. http://www.isdscotland.org/isd/5245.html [Accessed 17 January 2008]

7 Department of Health News Distribution Services. "£26.8 Million to improve access to contraception." 6 February 2008. http://nds.coi.gov.uk/environment/fullDetail.asp?ReleaselD=3507 21 \&News ArealD $=2$ \&NavigatedFromDepartment $=$ True [Accessed 17 January 2008].

8 Asker C, Stokes-Lampard H, Beavan J, Wilson S. What is it about intrauterine devices that women find unacceptable? Factors that make women non-users: a qualitative study. J Fam Plan Reprod Health Care 2006; 32: 89-94.

9 Hennink MM. International Focus Group Research. A Handbook for the Health and Social Sciences. Cambridge, UK: Cambridge University Press, 2007; 103.

10 Schunmann C, Glasier A. Measuring pregnancy intention and its relationship with contraceptive use among women undergoing therapeutic abortion. Contraception 2006; 73: 520-524.

11 Jones RK, Darroch JE, Henshaw SK. Contraceptive use among U.S. women having abortions in 2000-2001. Perspect Sex Reprod Health 2002; 34: 294-303.

12 Potter L, Oakley D, de Leon-Wong E, Canamar R. Measuring compliance among oral contraceptive users. Fam Plann Perspect 1996; 28: 154-158.

13 Tolaymat LL, Kaunitz AM. Long-acting contraception in adolescents. Curr Opin Obstet Gynecol 2007; 19: 453-460.

14 Larsson G, Blohm F, Sundell G, Andersch B, Milsom I. A longitudinal study of birth control and pregnancy outcome among women in a Swedish population Contraception 1997: 56: 6-16.

15 Darney PD, Callegari LS, Swift A, Atkinson ES, Robert AM. Condom practices of urban teens using Norplant contraceptive implants, oral contraceptives and condoms for contraception. Am J Obstet Gynecol 1998; 180: 929-937. 